Val 1483I I e pol ynor phi sm in the fatty aci $d$ synt hase gene was associ at ed wi th depressi ve sympt ons under the inf I uence of psychol ogi cal st ress

\begin{tabular}{|c|c|}
\hline 著者 & $\begin{array}{l}\text { Tsuboi Hi r ohi to, Sakaki bar a H r oyuki, } \\
\text { Yamakawa-Kobayashi Ki m ko, Tat sum Asami, } \\
\text { I namør i Tomøko, Hamanøt o Rei ko, Suzuki At suko, } \\
\text { Shi nøi Kayoko }\end{array}$ \\
\hline $\begin{array}{l}\text { jour nal or } \\
\text { publ i cat i on titl e }\end{array}$ & Journal of Affecti ve Di sorders \\
\hline vol une & 134 \\
\hline number & $1-3$ \\
\hline page $r$ ange & 448452 \\
\hline year & 2011- 11- 01 \\
\hline URL & ht t p: //hdl . handl e. net /2297/28329 \\
\hline
\end{tabular}




\section{Val1483Ile polymorphism in the fatty acid synthase gene was associated with depressive symptoms under the influence of psychological stress} Tomoko Inamori ${ }^{c}$, Reiko Hamamoto ${ }^{\text {, }}$, Atsuko Suzuki ${ }^{\text {, }}$ Kayoko Shimoi ${ }^{\text {b }}$

\footnotetext{
a Department of Drug Management and Policy, Institute of Medical Pharmaceutical and Health Sciences, Kanazawa University, Kanazawa, Japan

b Institute for Environmental Sciences, University of Shizuoka, Shizuoka, Japan

c School of Food and Nutritional Sciences, University of Shizuoka, Shizuoka, Japan

d Department of Community Health Nursing, Hamamatsu University School of Medicine, Hamamatsu, Japan

e Graduate School of Nutritional and Environmental Sciences, University of Shizuoka, Shizuoka, Japan
}

\section{A R T I C L E I N F O}

\section{Article history:}

Received 6 October 2010

Received in revised form 5 April 2011

Accepted 8 May 2011

Available online $\mathrm{xxxx}$

\section{Keywords:}

Lipid-metabolism

Stress

Depressive symptoms

5-HTTLPR gene

FASN gene

\begin{abstract}
A B S T R A C T
Background: To study the association between lipid-metabolism and depressive symptoms, genetic polymorphisms in serotonin transporter linked promoter region (5-HTTLPR) and fatty acid synthase gene (FASN) were investigated.

Method: A cross-sectional study was conducted on 177 women $(n=166)$ and men $(n=15)$ recruited from workers in a hospital and nursing homes in Japan. Depressive symptoms were assessed by the Center for Epidemiologic Studies Depression (CES-D) scale and perceived psychological stress was measured using visual analogue scale (VAS). The genotypes of 5HTTLPR (insertion/deletion; L/S), and FASN (Val1483Ile) were determined by the PCR methods. Linear regression analysis was performed, in which CES-D scores served as a dependent variable, and VAS scores, gene polymorphism, and confounders as independent variables. Results: Under the influence of perceived stress, S/S carriers of the 5-HTTLPR gene showed significantly higher CES-D scores in comparison with $\mathrm{L} / \mathrm{L}+\mathrm{L} / \mathrm{S}$ carriers $(F=8.2$, standardised beta $=0.15, p<0.05$ ). Regression analysis also confirmed that CES-D scores in participants with $\forall a / / V_{a}+$ Val/Ile genotypes of the FASN gene were significantly higher than those with He/lle, genotype $(F=8.4$, standardised beta $=0.16, p<0.05)$. In relation to physical features, BMI among participants with S/S genotype of 5-HTTLPR was significantly lower compared with those with $\mathrm{L} / \mathrm{L}+\mathrm{L} / \mathrm{S}$ genotypes.

Conclusions: The Val1483Ile polymorphism in the FASN was associated with depressive symptoms under the influence of psychological stress. The $S$ variant of 5-HTTLPR was related with less obese. (C) 2011 Published by Elsevier B.V.
\end{abstract}

\section{Introduction}

Literature suggested the association between depression and lipid metabolism: ex. lowered serum cholesterol levels were observed in depressive patients, particularly in those with suicidal behaviour (Fawcett et al., 1997), whereas the

\footnotetext{
* Corresponding author at: Department of Drug Management and Policy, Institute of Medical Pharmaceutical and Health Sciences, Kanazawa University, Kakuma-machi, Kanazawa-shi 920-1192, Japan. Tel./fax: +8176234 4403.

E-mail address:
}

comorbidity between depression and hyperlipemia was also 54 reported (Akbaraly et al., 2009). We are attempting to clarify 55 this association from the point of view of different genotypes. 56 Genetic variation in the $5^{\prime}$ flanking transcriptional region of 57 serotonin transporter gene (5-HTTLPR), which originates long 58 (L) and short $(\mathrm{S})$ alleles, plays a role in predisposition to major 59 depression in interaction with stressful life events (Caspi et al., 60 2003). The serotonergic system was hypothesised to regulate 61 behavioural and metabolic responses associated with the 62 development of obesity through feeding and satiety (Barsh 63 and Schwartz, 2002). Fatty acid (FA) metabolism may also 64

0165-0327/\$ - see front matter (C 2011 Published by Elsevier B.V.

doi:10.1016/j.jad.2011.05.010 
explain one of the mechanisms to link the psychological and somatic disorders. FA synthase (FAS), which is encoded by the FAS gene (FASN), is the central enzyme in de novo lipogenesis, catalysing the conversion of malonyl CoA into palmitate (Semenkovich, 1997). The Val1483Ile polymorphism in the FASN is linked to central obesity and insulin sensitivity, and putatively affects FAS action (Moreno-Navarrete et al., 2009). Although the evidence of the relationships between lipidmetabolism and affection remains controversial, it is relevant to reason on the biological pathway. The aim of this study was to investigate the common effects of the 5-HTTLPR and the FASN genes.

\section{Participants and methods}

A cross-sectional study was carried out on 177 women $(n=166)$ and men $(n=15)$ with a mean age of $42.4(S D 13.17)$, recruited from workers in a hospital and two nursing homes located in Shizuoka Prefecture, Japan. The Ethics Committee of University of Shizuoka approved the study protocol, and all participants gave informed consent to participate in this study.

Self-administrated questionnaire was distributed to the participants beforehand and answered one day before the examination day (working days), The questionnaire contains the demographic measures (age, gender, medication, etc.), lifestyle characteristics (smoking status: non-smoker or formertcurrent), current alcohol consumption: $\theta_{2}$ vs $\geq$ once per week, and leisuretime physical activity: < once per month $t_{\gtrless} \geq$ once per week, and psychological measures. Perceived stress was given using visual analogue scales $(10 \mathrm{~cm})$ anchored with "not at all" and "quite strong"; depressive symptoms were assessed with the center for Epidemiologic Studies Depression Scale (CES-D) (Matthews et al., 1985; Shima et al., 1985).

Fasting blood was sampled between 0830 and $1030 \mathrm{~h}$ from the forearm vein of each participant with a heparinized and serum-separator vacutainer tubes from which sera were 98 obtained by centrifugation. The sera samples were delivered 99 to a laboratory (FALCO Inc., Hamamatsu), and the heparinized 100 blood tubes were shipped to University of Shizuoka. Serum 101 triglycerides (TG) and total cholesterol (TC) were measured 102 enzymatically. High-density lipoprotein cholesterol (HDL-C) 103 and low-density lipoprotein cholesterol (LDL-C) were deter- 104 mined by the precipitation method using heparin-calcium. To 105 assess insulin resistance, the homeostasis model assessment of 106 insulin resistance (HOMA-IR) was used: fasting serum insulin 107 $(\mu \mathrm{U} / \mathrm{ml}) \times$ glucose $(\mathrm{mg} / \mathrm{dl}) / 405$ (Matthews et al., 1985). The 108 homeostasis model assessment of cell function (HOMA-ß) 109 was calculated as fasting serum insulin $(\mu \mathrm{U} / \mathrm{ml}) \times 360 /$ glucose 110 $(\mathrm{mg} / \mathrm{dl})-63)$ (Matthews et al., 1985). Leukocytes were 111 isolated from the heparinized blood by density centrifugation 112 by the method of English and Andersen (1974), as described by 113 Albrechtsen et al. (1988). Genomic DNA was then extracted 114 from the leukocytes using the phenol-chloroform extraction 115 method (Sambrook et al., Z006). The genotype of 5-HTTLPR 116 (insertion/deletion; $\mathrm{L} / \mathrm{S}$ ) was determined by amplified the 117 fragments including the polymorphisms by PCR. The FASN 118 genotype (Val1483lle, rs2228305) was determined by PCR- 119 restriction fragment length polymorphism analysis.

Data were analysed by the Japanese versions of SPSS (ver. 121 12.0.1) for Windows OS. For comparison of differences of 122 each genotype, analysis of covariance was utilised. Multiple 123 regression analysis was conducted to evaluate depressive 124 symptoms under the influence of perceived psychological 125 stress and covariates. A probability $p$ value less than 0.05 was 126 considered significant.

\section{Results}

Prior to data analysis, one person taking steroid contained 129 medicine, one participant ingesting Graves disease remedy, 130

Table 1

Characteristics of participants.

\begin{tabular}{|c|c|c|c|c|}
\hline & \multicolumn{2}{|l|}{ Female } & \multicolumn{2}{|l|}{ Male } \\
\hline & $n$ & Mean (SD) & $n$ & Mean (SD) \\
\hline Age & 162 & $43.2(13.09)$ & 15 & $33.8(12.951)$ \\
\hline BMI $\left(\mathrm{kg} / \mathrm{m}^{2}\right)$ & 162 & $22.4(4.00)$ & 15 & $23.8(4.95)$ \\
\hline Subjective stress (\%) & 162 & $57.9(25.36)$ & 15 & $62.4(29.97)$ \\
\hline Satisfacton of life (\%) & 162 & $57.1(23.21)$ & 15 & $53.0(26.21)$ \\
\hline Subjective sleep-quality (\%) & 162 & $65.8(28.86)$ & 15 & $73.6(23.55)$ \\
\hline CES-D scores & 162 & $14.9(6.95)$ & 15 & $16.6(9.32)$ \\
\hline \multicolumn{5}{|l|}{ Smoking status } \\
\hline No or ex-smoker & 120 & & 6 & \\
\hline Present smoker & 42 & & 9 & \\
\hline \multicolumn{5}{|l|}{ Current alcohol consumption } \\
\hline (almost) No & 140 & & 9 & \\
\hline$\geq$ Once per week & 21 & & 6 & \\
\hline \multicolumn{5}{|l|}{ Exercise } \\
\hline$<$ Once per month & 102 & & 6 & \\
\hline$\geq$ Once per week & 60 & & 9 & \\
\hline \multicolumn{5}{|l|}{ 5-HTTLPR gene polymorphisms } \\
\hline $\mathrm{L} / \mathrm{L}$ & $8(4.5 \%)$ & & $1(6.7 \%)$ & \\
\hline $\mathrm{L} / \mathrm{S}$ & $53(29.9 \%)$ & & $5(33.3 \%)$ & \\
\hline $\mathrm{S} / \mathrm{S}$ & $114(64.4 \%)$ & & $9(60.0 \%)$ & \\
\hline \multicolumn{5}{|l|}{ FASN gene polymorphisms } \\
\hline Val/Val & $159(89.8 \%)$ & & $12(80.0 \%)$ & \\
\hline Val/Ile & $14(7.9 \%)$ & & $3(20.0 \%)$ & \\
\hline Ile/Ile & $3(1.7 \%)$ & & $0(\theta)$ & \\
\hline
\end{tabular}


Table 2

Differences of psychological factors and indices related with metabolic syndrome between overall genotypes.

\begin{tabular}{|c|c|c|c|c|}
\hline \multirow[b]{2}{*}{ Genotype } & \multicolumn{2}{|l|}{ 5-HTTLPR } & \multicolumn{2}{|l|}{ FASN } \\
\hline & $\mathrm{S} / \mathrm{S}$ & $\mathrm{L} / \mathrm{L}+\mathrm{L} / \mathrm{S}$ & Val/Val & Val/Ile + Ile/Ile \\
\hline$n$ & 114 & 61 & 159 & 17 \\
\hline BMI $\left(\mathrm{kg} / \mathrm{m}^{2}\right)$ & $22.0(0.36)$ & $23.6(0.56)^{*}$ & $22.5(0.32)$ & $22.8(1.20)$ \\
\hline Subjective stress (\%) & $58.2(2.42)$ & $58.9(3.14)$ & $57.7(1.98)$ & $61.7(7.57)$ \\
\hline CES-D scores & $15.8(0.71)$ & $13.5(0.81) \stackrel{\text { 泟 }}{1}$ & $14.6(0.52)$ & $19.1(2.60)^{*}$ \\
\hline $\mathrm{TG}(\mathrm{mg} / \mathrm{dl})$ & $80.8(4.36)$ & $99.8(6.15) \stackrel{* *}{\perp}$ & $87.0(3.62)$ & 89.5 (15.99) \\
\hline $\mathrm{TC}(\mathrm{mg} / \mathrm{dl})$ & $211.2(3.67)$ & $221.1(5.82)$ & $215.7(3.36)$ & $205.8(7.84)$ \\
\hline HDL-C (mg/dl) & $74.0(1.67)$ & $70.7(2.38)$ & $73.2(1.44)$ & $70.0(4.19)$ \\
\hline LDL-C (mg/dl) & $120.4(2.99)$ & $130.1(4.83)$ & $124.5(2.79)$ & $117.7(5.59)$ \\
\hline Blood glucose $(\mathrm{mg} / \mathrm{dl})$ & 85.7 (1.17) & $91.3(3.75)$ & $87.6(1.65)$ & $87.8(2.56)$ \\
\hline $\mathrm{HbA1c}(\%)$ & $5.1(0.04)$ & $5.4(0.14)$ & $5.2(0.06)$ & $5.0(0.09)$ \\
\hline Insulin $(\mathrm{mg} / \mathrm{ml})$ & $6.03(0.352)$ & $7.35(0.952)$ & $6.55(0.439)$ & $5.71(0.762)$ \\
\hline HOMA-IR & $1.30(0.088)$ & $1.70(0.253)$ & $1.45(0.115)$ & $1.28(0.196)$ \\
\hline HOMA-ß & $115.5(8.73)$ & $93.6(18.50)$ & $109.4(9.40)$ & $89.1(10.75)$ \\
\hline
\end{tabular}

Results are expressed as mean (SE). Comparisons are controlling for age, gender, (BMI), smoking habit, alcohol consumption, and physical activities. BMI: body mass index. Subjective stress: perceived stress assessed using visual analogue scales anchored with "not at all" (0\%) and "quite strong" (100\%). 5-HTTLPR: Serotonin transporter gene linked polymorphism (L: long. S: short). FASA: Val(G)1483Ile(A) polymorphism in the fatty acid synthase gene. TG: Triglyceride. TC: total cholesterol. HDL-C: high-density lipoprotein cholesterol. LDL-C: low-density lipoprotein cholesterol. HOMA-IR: homeostasis model assessment of insulin resistance. HOMA-ß: homeostasis model assessment of lack of information for a few subjects.

* $p<0.05$.

慆 $p<0.1$.

and one who recently had a surgical operation were excluded; consequently, 162 female and 15 male participants were analysed. The characteristics of the sample are summarised in Table 1, together with the number of participants with data for each variable.

Table 2 exhibits the differences of variables concerning metabolic syndrome and psychological factors after controlling for gender, age and lifestyle factors. Since there were only nine subjects with L/L genotype of $5-H T T L P R$, the $\mathrm{L} / \mathrm{L}$ and $\mathrm{L} / \mathrm{S}$ genotypes were pooled and compared with the $\mathrm{S} / \mathrm{S}$ genotype in further analysis. In the same manner, FASN polymorphism was divided into Val/Val and Val/Ile + Ile/lle groups, and the dichotomized data were utilised for further analysis. As shown in Table 2, the subjects with S/S genotype of 5-HTTLPR exhibited significantly lower BMI in comparison with the $\mathrm{L} / \mathrm{L}+\mathrm{L} / \mathrm{S}$ genotypes $(p<0.05)$. In FASN, participants with Val/Ile + Ile/Ile genotypes presented significantly higher CES-D scores $(p<0.05)$ in comparison with those with $\mathrm{Val} / \mathrm{Val}$ genotypes.

Depressive symptoms under the influence of psychological stress were analysed by the linear regression analysis: the CESD scores as dependent variable, and subjective stress measured by VAS, gene polymorphism and covariates as independent 174 variables (Table 3); consequently, the S/S genotype of 5-HTTLPR 175 gene significantly contributed to depressive symptoms in 176 comparison with $\mathrm{S} / \mathrm{S}_{\mathrm{S}}+\mathrm{L} / \mathrm{L}$ genotypes under the influence of 177 psychological stress (Model 1: Standardised $\beta=0.15, p<0.05$ ). 178 Participants with the Val/Ile + Ile/Ile genotype in the FASN 179 revealed a significantly higher depressive symptoms in com- 180 parison with those with Val/Val under the psychological stress 181 (Model 2: Standardised $\beta=0.16, p<0.05$ ). Even though the 182 5-HTTLPR and FASN genotypes were put into the analysis model 183 together, each of them showed significance (Model 3: Standar- 184 dised $\beta=0.15, p<0.05$; Standardised $\beta=0.15, p<0.05)$; i.e., the 185 5-HTTLPR and the FASN were independently related with 186 depressive symptoms.

\section{Discussion}

It was found that participants with Val/Ile + Ile/lle genotypes 189 in the FASN showed higher depressive symptoms in comparison 190 with those with Val/Val genotype under the influence of 191 subjective psychological stress, and that participants with 5- 192

Table 3

Multivariate linear regression analyses showing the association of depressive symptoms with subjective stress and genotype $(n=174)$.

\begin{tabular}{|c|c|c|c|}
\hline \multirow[t]{2}{*}{ Gene polymorphism } & 5-HTTLPR (S/S: L/S + L/L) & FASN (Val/Val: He/He+Val/He) & \multirow{2}{*}{$\begin{array}{l}F \text { value and adjusted } \\
\Delta^{2} \text { value of each } \\
\text { regression model }\end{array}$} \\
\hline & Standardised $\beta$ & Standardised $\beta$ & \\
\hline Model 1 & $0.15^{*}$ & & $\begin{array}{l}F=8.2(8,169) \\
\Delta r^{2}=0.25\end{array}$ \\
\hline Model 2 & & $0.16^{*}$ & $\begin{array}{l}F=8.4(8,167) \\
\Delta r^{2}=0.25\end{array}$ \\
\hline Model 3 (Model 1 + Model 2) & $0.15^{*}$ & $0.15^{*}$ & $\begin{array}{l}F=8.0(9,165) \\
\Delta r^{2}=0.27\end{array}$ \\
\hline
\end{tabular}

Each model was adjusted by gender, age, BMI, leisure time physical activities, smoking habit and alcohol consumption. All models of overall genotypes are significant $(p<0.0005)$.

$* p<0.05$ 
HTTLPR S/S genotype exhibited higher depressive symptoms compared with those with $\mathrm{L} / \mathrm{S}+\mathrm{L} / \mathrm{L}$ genotypes. In addition, in $\mathrm{S} / \mathrm{S}$ participants, BMI was lower and serum TG levels appeared to be lower in comparison with $\mathrm{L} / \mathrm{S}+\mathrm{L} / \mathrm{L}$ participants.

5-HTTLPR S variant has been thought to be associated with susceptibility for depression (Canli and Lesch, 2007) since a longitudinal study revealed the vulnerability of $S$ variant to stressful life events (Caspi et al., 2003). The present study supports the result. In addition, our results indicated that 5 HTTLPR S variant eould, work to reduce obesity risks, though it is unsolved whether the 5-HTTLPR directly affect, obesityrelated index, or there were confounders between them. Discrepant results concerning the 5-HTTLPR variants and obesity were obtained in previous studies. Sookoian et al. (2008) showed that S/S carriers had higher body weights in comparison with $\mathrm{L} / \mathrm{L}$ carriers in obese $\left(\mathrm{BMI} \geq 27 \mathrm{~kg} / \mathrm{m}^{2}\right)$ group-of healthy male population. Lan et al. (2009) reported that $\mathrm{S} / \mathrm{S}$ genotype was a determinant of increased BMI level in non-elderly stroke patients. On the other hand, Bah et al. (2010) presented that $S$ allele tended to be more frequent in underweight persons among normal population. Discrepant results concerning 5-HTTLPR and BMH in previous studies might depend on participants' characteristics-such as healthy, having metabolic syndrome risks, etc. Since participants analysed in the current study were healthy volunteers, studies on normal population can support our results. Thus, it seems meaningless to discuss the relationships L allele and binge eating (Monteleone et al., 2006), or to think of the associations between $\mathrm{S}$ allele and anorexia nervosa (Hoffman et al., 2007) in relation to our results.

FASN gene encodes FAS, which is an enzyme in de novo lipogenesis (Semenkovich, 1997). Moreno-Navarrete, et al (2009) recently showed that the adipose tissue FAS activity was significantly higher in subjects with the Val variant in comparison with carriers of the Ile variant. In addition, Val allele in the FASN is linked with impaired glucose tolerance, visceral obesity etc. (Kovacs et al., 2004; Moreno-Navarrete et al., 2009). However, no differences were found between Val and Ile alleles in lipid and glucose-metabolism indices in this study. An interesting finding in the present study was that the FASN was related with depressive symptoms in the same degrees as the 5 HTTLPR under the influence of perceived stress, suggesting that Val1483Ile polymorphism in the FASN gene can affect the susceptibility to depression, and that the Ile variant may contribute to vulnerability to psychological stress. The pathway of the FASN effects on depressive symptoms is thought to differ from the one of 5-HTTLPR because each genotype was independently related with depressive symptoms as shown in model 3 of Table 3.

\section{Limitations and conclusion}

There are limitations in the eurrent study. Serotonin levels in the central nervous system were unknown. The number of male participants was small, which unavoidably put the gender factor as an independent variable of linear statistical models. Sample size could not be enough large to compare FASN alleles. Our results may be considered as preliminary, and further research is needed to confirm these findings. However, we presented possible relationships between depressive symptoms and FASN gene, and between BMI and 5-HTTLPR.

\section{Uncited reference}

Sambrooket al., 1989

\section{Role of funding source}

Funding for this study was provided primarily by a grant for the 255 Cooperation of Innovative Technology and Advanced Research in Evolutional 256 Area, and additionally by a grant-in-aid for Scientific Research, Ministry of 257 Education, Culture, Sports, Science and Technology, Japan. None of these 258 funding sources had a role in study design; in the collection, analysis and 259 interpretation of data; in the writing of the report; or in the decision to 260 submit the paper for publication.

Conflicts of interest

None of the authors have any conflicts of interest.

\section{Acknowledgement}

This research was primarily supported by a grant for the 265 Cooperation of Innovative Technology and Advanced Re- 266 search in Evolutional Area (city area) to K.S., and additional 267 support was provided by a grant-in-aid for Scientific Research 268 (C) 21500665 to H.T., Ministry of Education, Culture, Sports, 269 Science and Technology, Japan.

\section{References}

Akbaraly, T.N., Kivimäki, M., Brunner, E.J., Chandola, T., Marmot, M.G., Singh- 272 Manoux, A., Ferrie, J.E., 2009. Association between metabolic syndrome 273 and depressive symptoms in middle-aged adults: results from the 274 Whitehall II study. Diab. Care 32, 499-504.

Albrechtsen, M., Yeaman, G.R. Kerr, M.A, 1988. Characterization of the IgA 276 receptor from human polymorphonuclear leucocytes. Immunology 64, 277 201.

Bah, J., Westberg, L., Baghaei, F., Henningsson, S., Rosmond, R., Melke, J., 279 Holm, G., Eriksson, E., 2010. Further exploration of the possible influence 280 of polymorphisms in HTR2C and 5HTT on body weight. Metabolism 59, 281 1156-1163.

Barsh, G.S., Schwartz, M.W., 2002. Genetic approaches to studying energy 283 balance: perception and integration. Nat. Rev. Genet. 3, 589-600. 284

Canli, T., Lesch, K.P., 2007. Long story short: the serotonin transporter in 285 emotion regulation and social cognition. Nat. Neurosci. 10,1103-1109. 286

Caspi, A., Sugden, K., Moffitt, T.E., Taylor, A., Craig, I.W., Harrington, H., 287 McClay, J., Mill, J., Martin, J., Braithwaite, A., Poulton, R., 2003. Influence of 288 life stress on depression: moderation by a polymorphism in the 5-HTT 289 gene. Science 301, 386-389.

English, D., Andersen, B.R., 1974. Single step separation of red blood cells, 291 granulocytes and mononuclear leukocytes on discontinuous density 292 gradients of Ficoll-Hypaque. J. Immunol. Meth. 5, 249.

Fawcett, J., Busch, K.A., Jacobs, D., Kravitz, H.M., Fogg, L., 1997. Suicide: a four- 294 pathway clinical-biochemical model. Ann. N. Y. Acad. Sci. 836, 288-301. 295

Hoffman, J.B., Kaplan, J.R., Kinkead, B., Berga, S.L., Wilson, M.E., 2007. 296 Metabolic and reproductive consequences of the serotonin transporter 297 promoter polymorphism (5-HTTLPR) in adult female rhesus monkeys 298 (Macaca mulatta). Endocrine 31, 202-211.

Kovacs, P. Harper, I. Hanson, R. L, Infante, A.M., Bogardus, C., Tataranni, P.A., 300 Baier, L.J., 2004. A novel missense substitution (Val1483Ile) in the fatty 301 acid synthase gene (FAS) is associated with percentage of body fat and 302 substrate oxidation rates in nondiabetic Pima Indians. Diabetes 53, 303 1915-1919.

Lan, M.Y., Chang, Y.Y., Chen, W.H., Kao, Y.F., Lin, H.S., Liu, J.S., 2009. Serotonin 305 transporter gene promoter polymorphism is associated with body mass 306 index and obesity in non-elderly stroke patients. J. Endocrinol. Invest. 32, 307 119-122.

Matthews, D.R., Hosker, J.P., Rudenski, A.S., Naylor, B.A., Treacher, D.F., 309 Turner, R.C., 1985. Homeostasis model assessment: insulin resistance 310 and $\beta$-cell function from fasting plasma glucose and insulin concentra- 311 tion in man. Diabetologia 28, 412-419.

Monteleone, P., Tortorella, A., Castaldo, E., Maj, M., 2006. Association of a 313 functional serotonin transporter gene polymorphism with binge eating 314 disorder. Am. J. Med. Genet. B Neuropsychiatr. Genet. 141B, 7-9. 315

Moreno-Navarrete, J.M., Botas, P. Valdés, S., Ortega, FJ. Delgado, E. Vázquez- 316 Martín, A., Bassols, J., Pardo, G., Ricart, W., Menéndez, J.A., Fernández- 317 Real, J.M., 2009. Val1483Ile in FASN gene is linked to central obesity and 318 
insulin sensitivity in adult white men. Obesity 17, 1755-1761 (Silver Spring).

Sambrook, J., Fritsch, E.F., Maniatis, T., 1989. Molecular cloning. A laboratory manual2nd ed. Cold Spring Harbor Laboratory Press, New York.

Semenkovich, C.F., 1997. Regulation of fatty acid synthase (FAS). Prog. Lipid Res. 36, 43-53.
Shima, S., Shikano, T., Kitamura, T., Asai, M., 1985. New self-rating scale for 325 depression. Clin. Psychiatry 27, 717-723.

Sookoian, S, Gianotti, T.F, Gemma, C., Burgueño, A., Pirola, C.J., 2008. 327 Contribution of the functional 5-HTTLPR variant of the SLC6A4 gene to 328 obesity risk in male adults. Obesity 16, 488-491 (Silver Spring). 